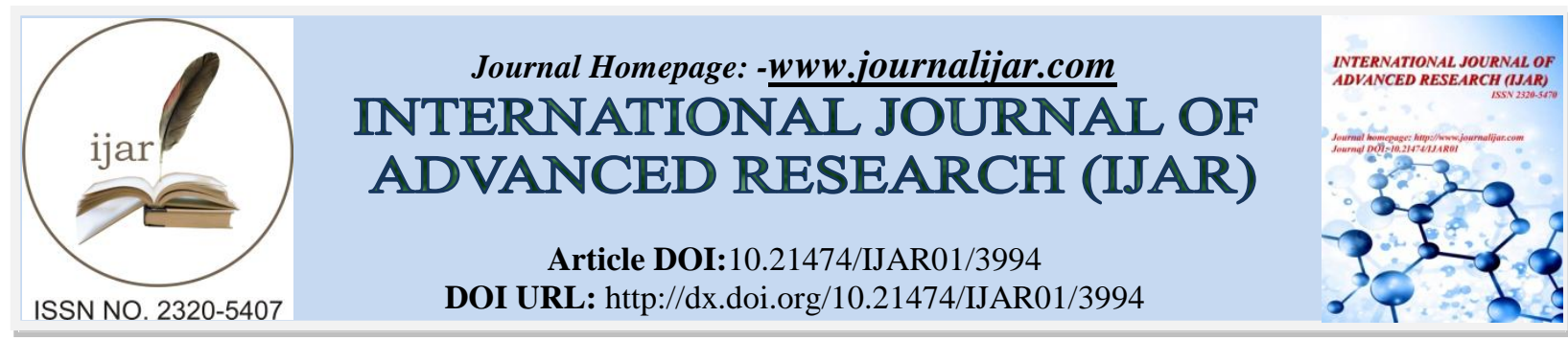

RESEARCH ARTICLE

\title{
BRIEF REVIEW OF SOLID ELECTROLYTE FOR LITHIUM ION BATTERIES IN PARTICULAR TO GARNET-STRUCTURED $\mathrm{Li}_{7} \mathrm{La}_{3} \mathrm{Zr}_{2} \mathrm{O}_{12}$ SOLID-STATE ELECTROLYTE.
}

\author{
*Tulu Wegayehu' ${ }^{1}$, Yonatan Mulushoa ${ }^{1}$, N.Murali ${ }^{2}$, B.Vikram Babu $^{1}$ and T.Arunamani ${ }^{1}$. \\ 1. Department of physics, Andhra University, Visakhapatnam-530003, India. \\ 2. Analytic laboratory,Andhra University, Visakhapatnam-530003, India.
}

\section{Manuscript Info}

Manuscript History

Received: 15 February 2017

Final Accepted: 20 March 2017

Published: April 2017

Key words:-

Garnet-structured, $\mathrm{Li}_{7} \mathrm{La}_{3} \mathrm{Zr}_{2} \mathrm{O}_{12}$, Ionic conductivity

\begin{abstract}
In this review work it has been tried to briefly summarize solid state electrolytes conductivity status. As the very essential component for battery efficiency and performance, electrolytes need be given due attention as safety problems could also emanate from it as well. The oxide solid state electrolytes are very promising electrolytes for allsolid-state batteries for large applications. The garnet-structured $\mathrm{Li}_{7} \mathrm{La}_{3} \mathrm{Zr}_{2} \mathrm{O}_{12}$ has shown high ionic conductivity that is comparable to the liquid electrolytes with large potential windows. At lower temperature $\mathrm{Li}_{7} \mathrm{La}_{3} \mathrm{Zr}_{2} \mathrm{O}_{12}$ will have high Li-ordered and forms the tetragonal structure which is less ionic conductor as compared to the less Li-ordered cubic structure. A total ionic conductivity of the order of $10^{-3} \mathrm{Scm}^{-1}$ has been achieved by the cubic structures of $\mathrm{Li}_{7} \mathrm{La}_{3} \mathrm{Zr}_{2} \mathrm{O}_{12}$ which will let it to be applicable in practice.
\end{abstract}

Copy Right, IJAR, 2017,. All rights reserved.

\section{Introduction:-}

Energy and energy sources are far more in need especially in this modern society. Whether could it be portable or grid storage beyond national security agenda, it is all about question of life. So far the fossil has dominated the source of energy which has brought a huge environmental impact by releasing $\mathrm{CO}_{2}$ and other gases into the atmosphere which cause depletion of ozone layer. So the use of fossil fuels has flooded the planet with global warming which will end up with devastating consequences unless some measures are taken by using alternative energy sources [1-3].

Battery technology is one source and storage of energy that especially is used for portable electronic devices and even for electric vehicles. From the first rechargeable lead-acid battery to the recently developed lithium ion secondary batteries, we have different battery systems; and the lithium-ion batteries are the state-of-art technology batteries with high energy and power density with high performance. Very recently Lithium-air and Lithium-sulfur batteries are developed with higher energy density than lithium-ion batteries [4].

In this review a focus on the recent concepts on lithium ion battery and its solid state electrolyte component has been given. The solid state electrolytes with the garnet structure in particular the Lithium lanthanum zirconate $\left(\mathrm{Li}_{7} \mathrm{La}_{3} \mathrm{Zr}_{2} \mathrm{O}_{12}\right)$ conductivity will be the premise of this review. It is very important to deal with the safety concerns of batteries in general; and the above mentioned material is highly promising excellent ionic conductor and sounds good to discuss on it. 


\section{Lithium-Ion Battery and Its Components:-}

Rechargeable lithium ion (Li-ion) batteries are the most important and promising parts of energy storage for portable electronic devices and electric vehicles. They are also became the hearts of entertainment, telecommunication and computing equipment of this modern dynamic society. Currently the worldwide market of this battery types has reached about 10 billion dollars per year. High energy densities and cyclic performances are the main reasons for such huge market coverage $[1,2]$. Although such an impressive market value, the science underlying the battery technology is advancing at slower pace [2].

An important science lying under the lithium ion batteries is the so called intercalation chemistry. This is where a metal oxide incorporates lithium ions in its structure while its structure is not being affected so that the lithium ions move in and out without much or not at all distorting the host structure. Such Lithium-insertion compounds as positive electrode materials have been developed by the mid-1970s [3]. Very importantly the secondary lithium ion batteries contain three major components: the positive electrode (cathode), the negative electrode (anode), and an ionically conducting material (electrolyte). In case of the liquid electrolytes, the thin sheets of microporous polymer separators are very important as filters to allow Li-ions to pass through them and block electronic passage. The challenges in making high density rechargeable batteries is not only due to the difficulty of increasing density while reducing its mass but also it is the less potential windows of the electrolytes. Here in the following is the schematic diagram how the Li-ion battery components are brought together and work during charging:

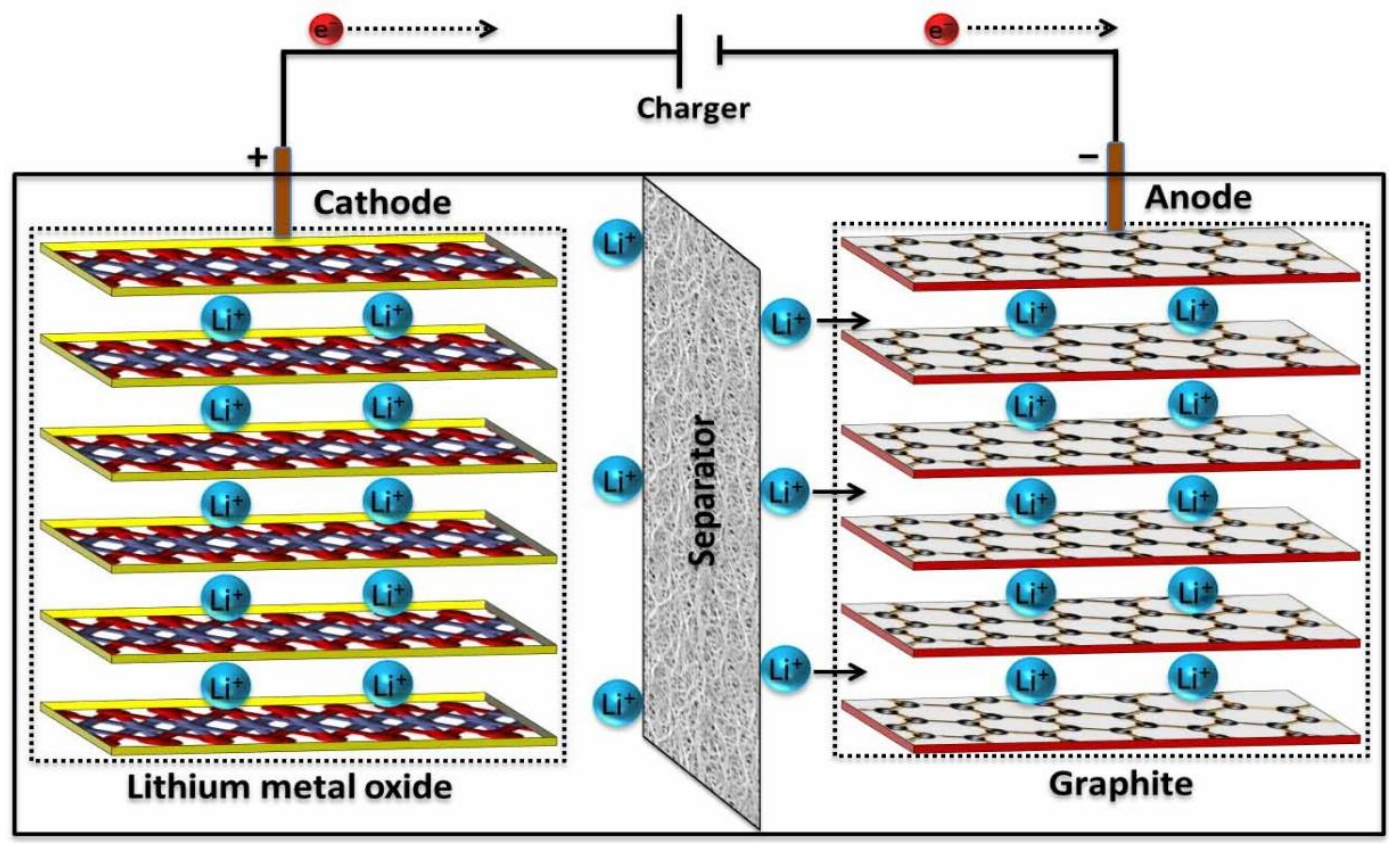

Figure 1:- Schematic representation of lithium ion battery components (ref. ViPER Group)

The whole charging and discharging processes are accompanied by the reduction and oxidation reactions at the two electrodes. The point is how easily a cathode material is oxidized when the battery is charged and the reverse process occurring at the anode. Therefore, the easier an oxidation-reduction processes exhibited by the electrode materials of a battery and the ability to accommodate more Li-ions without any significant structural change, the simplest will be getting high-energy and efficient battery systems $[3,5]$.

Recently, in a strive to make cost effective, thermally stable, high-energy and efficient cathode materials lots of experimental and theoretical investigations on materials are undergoing. The first cathode material commercialized by Sony in 1991 was $\mathrm{LiCoO}_{2}$; and it has low thermal stability, high cost, high toxicity, and low specific energy [5]. Therefore, it was straightforward either to change the toxic Co or at least reduce its content by partial substitutions. As a result, the layer structured $\mathrm{LiNiO}_{2}$, the spinel structured $\mathrm{LiMn}_{2} \mathrm{O}_{4}$, and olivine structured $\mathrm{LiFePO}_{4}$ have been produced $[6,7]$. But more than these mentioned cathode materials, the $\mathrm{LiNi}_{1 / 3} \mathrm{Co}_{1 / 3} \mathrm{Mn}_{1 / 3} \mathrm{O}_{2}$ has been developed and studied to be most promising cathode material with better cyclability performance, milder thermal stability, lower cost, less toxicity, and up to $200 \mathrm{mAh} / \mathrm{g}$ capacity [8]. 


\section{Electrolytes and Their Types:-}

Among the three major components of the lithium-ion batteries the electrolytes takes the lion's share for the safety concern of the battery and besides, their properties are key determinants of battery performance [9]. Therefore, it will be reasonable to go thoroughly and study electrolyte properties by classifying them in some sort of parameters.

Broadly, we can classify electrolyte for lithium ion batteries as liquid types, solid types and polymer types (Gel types). The organic solvent based liquid electrolytes are more of applicable in most lithium ion batteries currently. These solvents include ethylene carbonate (EC), dimethyl carbonate (DMC), etc and in this solvents the lithium salts like $\mathrm{LiClO}_{4}$ or $\mathrm{LiPF}_{6}$ are dissolved in so that the electrolyte of high ionic conductivity will be formed. The oxidation/reduction potential of an electrolyte system is very important and it has been determined for these electrolytes by a potential sweep method in the potential ranges of 3 to $6 \mathrm{~V}$ with a sweep rate of $0.1 \mathrm{mV} / \mathrm{s}$ [10].

The melting and boiling points of the solvents also affects the working temperature of the battery and obviously an electrolyte is preferred to have low melting point and high boiling point and a wide working temperature range. In addition, organic electrolytes are expected to exhibit high dielectric constant and low viscosity so that their ionic conductivity will be enhanced [11].

The other groups of electrolyte that allow the fabrication of plastic batteries are the so called polymer electrolytes. The polymer electrolytes have good mechanical properties, high ionic conductivity, wide electrochemical stability, low cost, and benign chemical composition [10]. The basic difference between the liquid and polymer electrolytes lies on the mechanical stiffness of the polymer electrolytes. Polymer electrolyte could be either hard-to-solid electrolyte or combinations of solids and molten in phase equilibrium [12]. But still some scholar prefers to call polymer electrolytes as solid electrolytes.

Solid electrolyte types have been introduced to resolve the safety problems and easy of mechanical designing of batteries. Brief details of this type of electrolytes are presented in the following section.

\section{Ceramic Electrolytes:-}

The solid state electrolyte types are very promising as a solution to the safety problems of lithium ion batteries especially at elevated temperatures. In general solid state lithium ion conducting electrolyte that is used to make allsolid-state lithium ion batteries should exhibit the following physical and electrical properties:

1. High lithium ion conductivity at room temperature and less or almost no electronic conductivity.

2. High potential windows at both negative and positive electrodes.

3. Environmentally benign, nonhygroscopic, low cost and ease of preparation [13].

Table 1:- Ionic conductivities of typical inorganic lithium-ion conductors [ref 13].

\begin{tabular}{|c|c|c|c|}
\hline Lithium-ion conductors & $\boldsymbol{\sigma}_{\text {ion }}\left(\mathbf{S c m}^{-1}\right)$ at R.T & Researchers & Year \\
\hline $\mathrm{LiI}$ & $1 \times 10^{-7}$ & Ginnings and Phipps & 1930 \\
\hline $\mathrm{Li}-\beta_{\mathrm{AAl}} \mathrm{O}_{3}$ & $3 \times 10^{-3}$ & Yao and Kummer & 1967 \\
\hline $\mathrm{Li}_{3} \mathrm{~N}$ & $10^{-3}$ & Alpen and Muller & 1977 \\
\hline $\mathrm{Li}_{14} \mathrm{Zn}\left(\mathrm{GeO}_{4}\right)_{4}(\mathrm{LISICON})$ & $2 \times 10^{-6}($ at $323 \mathrm{~K})$ & Hong & 1978 \\
\hline $4.9 \mathrm{LiI}-34.1 \mathrm{Li}_{2} \mathrm{O}-61 \mathrm{~B}_{2} \mathrm{O}_{3}$ & $2 \times 10^{-7}$ & Malgani and Robert & 1979 \\
\hline $\mathrm{Li}_{3.6} \mathrm{Ge}_{0.6} \mathrm{~V}_{0.4} \mathrm{O}_{4}$ & $4 \times 10^{-5}$ & Kuwano and West & 1980 \\
\hline $0.30 \mathrm{Li}_{2} \mathrm{~S}_{-}-2.26 \mathrm{~B}_{2} \mathrm{~S}_{3}-0.44 \mathrm{LiI}$ & $1.7 \times 10^{-3}$ & Wada et al & 1983 \\
\hline $\mathrm{LiTi}_{2}\left(\mathrm{PO}_{4}\right)_{3}$ & $2 \times 10^{-6}$ & Subramanian et al & 1986 \\
\hline $60 \mathrm{Li}_{2} \mathrm{~S}_{4}-40 \mathrm{SiS}_{2}$ & $4 \times 10^{-4}$ & Pradel and Ribes & 1986 \\
\hline $\mathrm{Li}_{1.3} \mathrm{Al}_{0.3} \mathrm{Ti}_{1.7}\left(\mathrm{PO}_{4}\right)_{3}$ & $7 \times 10^{-4}$ & Aono et al. & 1989 \\
\hline $0.02 \mathrm{Li}_{3} \mathrm{PO}_{4}-0.98\left(\mathrm{Li}_{2} \mathrm{~S}_{-} \mathrm{SiS}_{2}\right)$ & $7.6 \times 10^{-4}$ & Takada et al. & 1993 \\
\hline
\end{tabular}

In table 1 are some of the solid or ceramic electrolytes and their ionic conductivities. These groups of electrolyte are oxides, Thio-LISCONS, glass ceramics, and some other sulphide types. But in general we can classify ceramic electrolytes as oxides, phosphate, and sulphides [9]. At this point we better high-light the oxide group perovskite type solid electrolytes as they are one of the promising electrolytes for all-solid-state batteries. 
Perovskites are those solid state electrolytes named after the Russian mineralogist Lev Perovki. They have a general chemical formula of $\mathrm{ABO}_{3}$. Ideally, they crystallize into cubic structure with unit cell of side length about $3.9 \AA$ and space group of $P m 3 m$ [14]. Lithium lanthanum titanate, $\mathrm{Li}_{3 \mathrm{x}} \mathrm{La}_{(2 / 3)-\mathrm{x}} \mathrm{TiO}_{3}(0.04<\mathrm{x}<0.16)$ (LLT) which is a perovskite structured solid state electrolyte showed high ionic conductivity, on the order of $10^{-3} \mathrm{Scm}^{-1}$, taking advantage of favorable lithium-ion hopping via $A$-sites in the perovskite structure $[9,13]$. Such conductivity is just comparable to the conductivity of the liquid electrolyte types. A lot of effort has been underway to increase the conductivity of these types of electrolytes by doping appropriate materials in either the titanium- or lithium- and even at the oxygen-sites of this compound. Ultimately all the doping efforts should bring A-site vacancy so that it will let the lithium-ions to hop in the structure thereby making them ionically conducting species.

The garnet structured oxide solid state electrolytes have recently been discovered and they are also promising electrolyte for lithium ion batteries. They have a general chemical formula $\mathrm{A}_{3} \mathrm{~B}_{2} \mathrm{C}_{3} \mathrm{O}_{12}$ and could have either cubic or tetragonal structures based on the synthesis process or their specific compositions and physical parameters. Among these garnet structured oxides the $\mathrm{Li}_{7} \mathrm{La}_{3} \mathrm{Zr}_{2} \mathrm{O}_{12}$ has shown high chemical stability against lithium metal besides its high ionic conductivity. The cubic polymorph of this material is by far more ionically conductive than the tetragonal structure $[15,16]$.
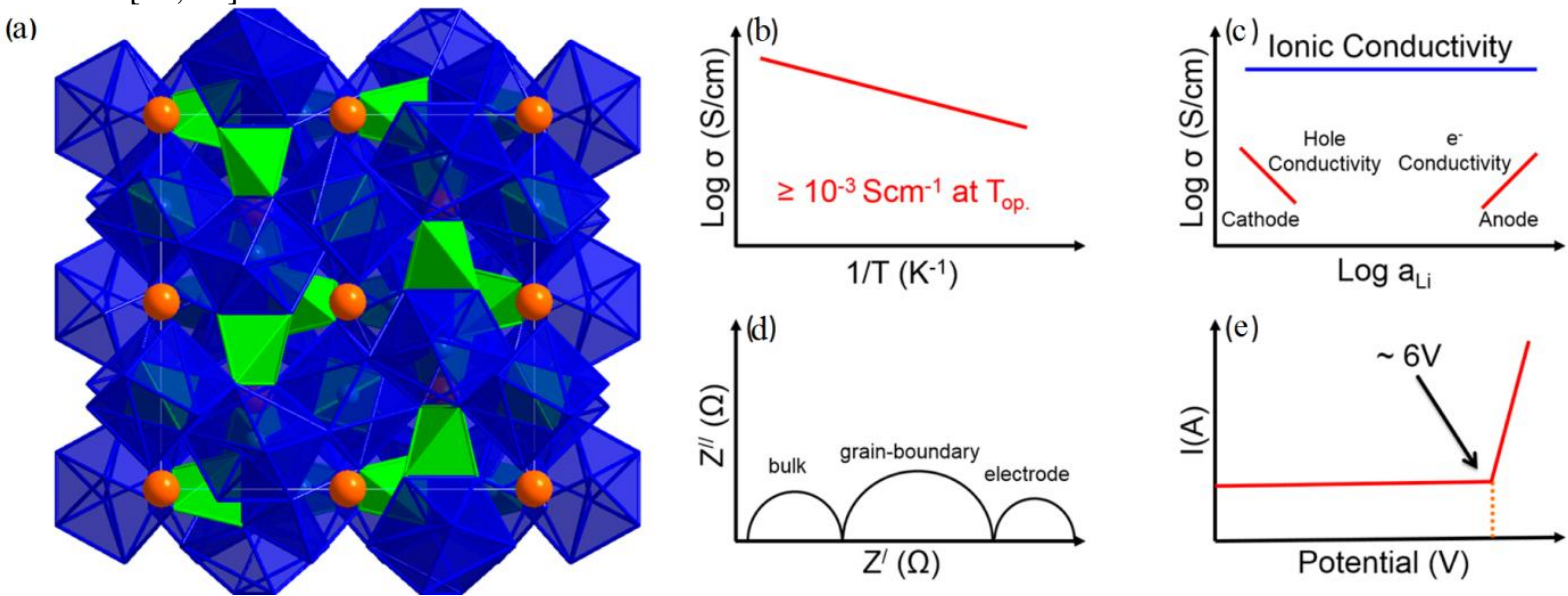

Figure 2:- (a) Crystal structure of an ideal garnet of general formula $\mathrm{A}_{3} \mathrm{~B}_{2} \mathrm{C}_{3} \mathrm{O}_{12}$, where the orange spheres represent $\mathrm{B}$ cations and blue and green polyhedrons represent $\mathrm{A}$ and $\mathrm{C}$ cations, respectively, (b) a schematic representation showing high total ionic conductivity of $\geq 10^{-3} \mathrm{~S} \mathrm{~cm}^{-1}$ at the operating temperature $\left(\mathrm{T}_{\mathrm{op}}\right)$ of the battery, (c) predominately $\mathrm{Li}$ ion conduction; electronic conductivity should be negligible over a wide range of $\mathrm{Li}$ ion activities, (d) negligible grain boundary contribution to total impedance and low electrolyte-electrode charge-transfer impedance, and (e) electrochemical stability up to $6 \mathrm{~V}$ [17].

There has been several synthesis techniques employed to produce the nominal composition $\mathrm{Li}_{7} \mathrm{La}_{3} \mathrm{Zr}_{2} \mathrm{O}_{12}$ and lots of reports have been describing the solid state route (ceramic method) in synthesis of the two polymorphs. The higher temperature synthesis route results in usually the cubic structure stabilized by dopants such as $\mathrm{Al}^{3+}$ by contamination from $\mathrm{Al}_{2} \mathrm{O}_{3}$ crucibles. Of course, there are several parameters that determine the cubic structure but very importantly the calcination temperature is taking the main share [16]. The less Li-ordering structure helps for vacancy formation for lithium-ions to hop as conduction mechanism in the cubic structure of $\mathrm{Li}_{7} \mathrm{La}_{3} \mathrm{Zr}_{2} \mathrm{O}_{12}$. Table 2 below describes the synthesis techniques and the resulting structure of $\mathrm{Li}_{7} \mathrm{La}_{3} \mathrm{Zr}_{2} \mathrm{O}_{12}$.

Table 2:- Synthesis methods and structures of nominal composition $\mathrm{Li}_{7} \mathrm{La}_{3} \mathrm{Zr}_{2} \mathrm{O}_{12}$ [ref. 16]

\begin{tabular}{|l|l|l|l|l|l|}
\hline $\begin{array}{l}\text { Synthesis } \\
\text { techniques }\end{array}$ & Temperature ${ }^{\mathbf{0}} \mathbf{C}$ & Al moles & Li moles & Tetragonal & Cubic \\
\hline Pechini & 700 & & & & $\mathrm{x}$ \\
\hline Pechini & 800 & & & $\mathrm{x}$ & \\
\hline Pechini & 800 & - & $7.0,7.5$ & $\mathrm{x}$ & \\
\hline Pechini & 900 & & & $\mathrm{x}$ & \\
\hline Pechini & 1180 & 0.23 & 5.96 & & $\mathrm{x}$ \\
\hline Solid state & 900 & & & $\mathrm{x}$ & \\
\hline Solid state & 980 & & & $\mathrm{x}$ & \\
\hline
\end{tabular}




\begin{tabular}{|l|l|l|l|l|l|}
\hline Solid state & 1125 & & & $\mathrm{x}$ & \\
\hline Solid state & 1200 & & & & $\mathrm{x}$ \\
\hline Solid state & 1230 & $0.074-0.15$ & - & $\mathrm{x}$ & \\
\hline Solid state & 1230 & 0.19 & 6.27 & & $\mathrm{x}$ \\
\hline Solid state & 1230 & 0.40 & - & & $\mathrm{x}$ \\
\hline Solid state & 1230 & & & & $\mathrm{x}$ \\
\hline
\end{tabular}

From the three dimensional sub network the Li atoms occupy the tetrahedral and octahedral sites where as the La atoms occupy dodecahedral sites formed by eight $\mathrm{O}$ atoms and $\mathrm{Zr}$ atoms occupying the octahedral sites (96h). Besides, the cubic structure of $\mathrm{Li}_{7} \mathrm{La}_{3} \mathrm{Zr}_{2} \mathrm{O}_{12}$ crystalizes into Ia3d space group whereas the tetragonal one crystalizes into $\mathrm{I}_{1} /$ acd [18].

As shown in figure 2(b-e), the electrical responses of this garnet structured solid electrolyte is assumed to exhibit in such depicted patterns. It has been reported that both experimental and theoretical investigations suggest that the conductivity of $\mathrm{Li}_{7} \mathrm{La}_{3} \mathrm{Zr}_{2} \mathrm{O}_{12}$ depends on the content of Li-ions [17]. The impedance spectroscopy is the indirect measure of the ionic diffusion in solids and in this case the $\mathrm{Li}_{7} \mathrm{La}_{3} \mathrm{Zr}_{2} \mathrm{O}_{12}$ shows lower impedance pattern at higher frequencies implying less time for the ions to reorient themselves and get polarized [19]. Whereas for low frequencies usually there is a tail formed showing an ionic blocking thereby stating ionic conduction of the material but in this case (figure 2d) the electrode contribution is showing higher impedance and semicircle signifying the ionic conduction of the electrodes. Both ionic and electronic conductivities could be exhibited by electrodes.

At this point we need raise few questions that we assume should be addressed thoroughly and might be the science of all-solid-state batteries. The first is, in constructing a solid-state batteries, it is inevitable to talk about the Li-ion conduction; so which lithium is employed in the conduction process? Is that the one found in the electrodes or in the solid electrolyte, $\mathrm{Li}_{7} \mathrm{La}_{3} \mathrm{Zr}_{2} \mathrm{O}_{12}$ ? Secondly, what about the difference between "the conduction Li-ions" and the Liion that makes up the structure of the solid electrolyte? It is like the analogy in the difference between the conduction electrons and valence electrons; of course, this one is quantum mechanical aspect. Despite the details of the $\mathrm{Li}^{+}$source and exact mechanism of conduction, good conductivities of solid electrolyte materials have been achieved.

In recent research reports, Ta-doped $\mathrm{Li}_{7} \mathrm{La}_{3} \mathrm{Zr}_{2} \mathrm{O}_{12}$ has shown to conduct at room temperature of about $6.1 \times 10^{-4} \mathrm{Scm}^{-1}$ [20]. Also EzhiylRangasamy, et al. reported a conductivity of $4 \times 10^{-4} \mathrm{Scm}^{-1}$ [16]. Stressing on the effect of $\mathrm{Li}^{+}$ concentration on the conductivity of Al-doped $\mathrm{Li}_{7} \mathrm{La}_{3} \mathrm{Zr}_{2} \mathrm{O}_{12}$, Yanhua Zhang, et al., have come up with a conductivity of $1.3 \times 10^{-3} \mathrm{Scm}^{-1}$ [21]. Other groups by Ga-doping achieved an ionic conductivity of $\sim 5 \times 10^{-4} \mathrm{Scm}^{-1}$ [22].

Synthesizing at high temperatures, the Yanhua Zhang, et al., group also produced highly dense cubic $\mathrm{Li}_{7} \mathrm{La}_{3} \mathrm{Zr}_{2} \mathrm{O}_{12}$ solid electrolyte of conductivity $5.7 \times 10^{-4} \mathrm{Scm}^{-1}$ with activation energy of $0.3 \mathrm{eV}$ [23]. By doping tungsten (W), Yiqiu Li, et al., group has found a total ionic and electronic conductivities of $6.6 \times 10^{-4} \mathrm{Scm}^{-1}$ and $1.9 \times 10^{-8} \mathrm{Scm}^{-1}$, respectively; and activation energy of $0.42 \mathrm{eV}$ [24].

Using a solid state synthesis route and doping $\mathrm{Ta}$ and $\mathrm{Nb}$ at $\mathrm{Zr}$-site of $\mathrm{Li}_{7} \mathrm{La}_{3} \mathrm{Zr}_{2} \mathrm{O}_{12}$, Mian Huang, et al., have found a conductivity of about $1.2 \times 10^{-3} \mathrm{Scm}^{-1}$ at some higher temperature [25]. Others also tried to dope $\mathrm{F}$ at $\mathrm{O}$-site of this compound and came up with a total conductivity of $5 \times 10^{-4} \mathrm{Scm}^{-1}$ [26]. By doping $\mathrm{Al}$ and stabilizing the cubic phase at higher temperature Yasuaki Matsuda, et al., have come up with total ionic conductivity of $\mathrm{Li}_{6.25} \mathrm{Al}_{0.25} \mathrm{La}_{3} \mathrm{Zr}_{2} \mathrm{O}_{12}$ in the order of $2.1 \times 10^{-4} \mathrm{Scm}^{-1}$ at $25{ }^{\circ} \mathrm{C}$ [27]. Garnet-structured solid electrolytes of conductivities in the order of $10^{-}$ ${ }^{7} \mathrm{Scm}^{-1}-10^{-5} \mathrm{Scm}^{-1}$ have been listed in VenkataramanThangadurai, et al., review work [17] but here we have tried to communicate some of best ionic conductors of the $\mathrm{Li}_{7} \mathrm{La}_{3} \mathrm{Zr}_{2} \mathrm{O}_{12}$ doped groups.

\section{Conclusions:-}

Energy storage has been produced in different forms and obviously it is in response to the unprecedented need for such energy sources by the present day society. But the energy sources and storage devices have to be safe and reliable for high applications as well. Lithium ion batteries are the very efficient energy sources for portable electronic devices and electric vehicles. As reported in the news at different occasions these batteries have at times found catching fire due to overheating and abusive conditions. 
Therefore, there is a need to study the electrolyte component of these batteries as it is this electrolyte that erupts to catch fire. The solid electrolyte are the ultimate solutions to the safety problems that these batteries facing. The oxide type solid electrolytes are the most stable and promising electrolyte types for lithium ion batteries. The garnetstructured $\mathrm{Li}_{7} \mathrm{La}_{3} \mathrm{Zr}_{2} \mathrm{O}_{12}$ are most recent high ionically conducting solids with high potential windows and high temperature applications.

The so mentioned material could be synthesized with different synthesis methods and has shown to exhibit good ionic conductivity as reported by different research out puts. Conductivities of the order $10^{-3} \mathrm{Scm}^{-1}$ have been achieved by these oxide garnet structured $\mathrm{Li}_{7} \mathrm{La}_{3} \mathrm{Zr}_{2} \mathrm{O}_{12}$ materials and such good conductivity lets these materials be applicable to large energy storage and power sources.

In brief, we assume it has been conveyed that energy sources from lithium ion batteries are crucially in need and such energy storage devices to work in safe mood, their electrolyte components should be very stable thermally, high ionically conductive, low cost, electrochemically stable, and large potential windows. Besides, the solid electrolyte $\mathrm{Li}_{7} \mathrm{La}_{3} \mathrm{Zr}_{2} \mathrm{O}_{12}$ is most promising for and even applicable in all-solid-state batteries.

\section{References:-}

1. J.M. Tarascon\& M. Armand, insight review articles, Nature, 414, (2001).

2. Walter A. van Schalkwijk and Bruno Scrosati, Advances in Lithium-Ion Batteries, Kluwer Academic Publishers, 2002.

3. C. Julien and Z. Stoynov, Materials for Lithium-Ion Batteries, Springer Science+Business Media Dordrecht, 2000.

4. Katharina Meier, TeodoroLaino, and Alessandro Curioni, J. Phys. Chem. C 118 (2014), 6668-6679.

5. Chien-Te Hsieh, Chung-Yu Mo, Yu-Fu Chen, Yi-Jou Chung, ElectrochimicaActa106 (2013) 525- 533.

6. Otoo Yamada, Masashi Ishikawa, Masayuki Morita, ElectrochimicaActa44 (1999) 1607-1615.

7. M.V. Reddy, Thor Wei Jie, Charl J. Jafta, Kenneth I. Ozoemena,Mkhulu K. Mathe, A. Sreekumaran Nair, Soo Soon Peng, M. SobriIdris,GeethaBalakrishna, Fabian I. Ezema, B.V.R. Chowdari, ElectrochimicaActa128 (2014) 192-197.

8. Long Tan, Haowen Liu, Solid State Ionics 181 (2010) 1530-1533.

9. Xianxia Yuan, Hansan Liu, and Jiujun Zhang, Lithium-Ion Batteries Advanced Materials and Technologies, CRC Taylor and Francis Group, 2014.

10. Walter A. van Schalkwijk and Bruno Scrosati, Advances in Lithium-Ion Batteries, Kluwer Academic Publishers, 2002.

11. Yuping Wu, Lithium-Ion Batteries Fundamentals and Applications, CRC Press Taylor and Francis Group, 2015.

12. Claus Daniel and Jurgen O. Besenhard, Handbook of Battery Materials, Wiley-VCH Verlag\& Co. KGaA, 2011.

13. Chong Rae Park, Next Generation Lithium Ion Batteries for Electrical Vehicles, In-the, 2010.

14. K. VijayaBabu, V. Veeraiah and P.S.V. SubbaRao, ACTA PHYSICA POLONICA A, 122 (2012).

15. Joong Sun Park, Lei Cheng, Vassilia Zorba, Apurva Mehta, Jordi Cabana, Guoying Chen, Marca M. Doeff, Thomas J. Richardson, Jung Hoon Park, Ji-Won Son, Wan-Shick Hong, Thin Solid Films 576 (2015) 55-60.

16. EzhiylRangasamy, Jeff Wolfenstine, Jeffrey Sakamo, Solid State Ionics 206 (2012) 28-32.

17. VenkataramanThangadurai, Dana Pinzaru, Sumaletha Narayanan, and Ashok Kumar Baral, J. Phys. Chem. Lett. 6 (2015) 292-299.

18. G. Larraz, A. Orera and M. L. Sanjuan, J. Mater. Chem. A, 1(2013) 11419.

19. Patrick Bottke,Daniel Rettenwander,Walter Schmidt,Georg Amthauer,and Martin Wilkening, Chem. Mater. 27(2015) 6571-6582.

20. Ryoji Inada, Koji Kusakabe, Takayuki Tanaka, ShotaKudo, and Yoji Sakurai, Proceedings of The 19th International Conference on Solid State Ionics (SSI-19), September 2013.

21. Yanhua Zhang, Fei Chen, RongTu, QiangShen, Xulong Zhang, Lianmeng Zhang, Solid State Ionics 284 (2016) 53-60.

22. Hany El Shinawi, Jürgen Janek, Journal of Power Sources 225 (2013) 13-19.

23. Yanhua Zhang, Fei Chen, RongTu, QiangShen, Lianmeng Zhang, Journal of Power Sources 268 (2014) 960964.

24. Yiqiu Li, Zheng Wang, Yang Cao, Fuming Du, Cheng Chen, Zhonghui Cui, XiangxinGuo, ElectrochimicaActa180 (2015) 37-42. 
25. Mian Huang, Mao Shoji, Yang Shen, Ce-Wen Nan, HirokazuMunakata,Kiyoshi Kanamura, Journal of Power Sources 261 (2014) 206-211.

26. LIU Cai, WEN Zhao-Yin, RUI Kun, Journal of Inorganic Materials, 30 (2015).

27. Yasuaki Matsuda, Kimie Sakamoto, Masaki Matsui, Osamu Yamamoto, Yasuo Takeda, Nobuyuki Imanishi, Solid State Ionics 277 (2015) 23-29. 